\title{
Entrevista com Tania Regina de Souza Romero, professora da Universidade Federal de Lavras, em homenagem aos 10 anos do Programa de Mestrado Profissional em Educação da UFLA
}

\section{Interview with Tania Regina de Souza Romero, teacher at the Universidade Federal de Lavras, in honor of the 10 years of the Professional Master's Program in Education at UFLA}

\author{
Tania Regina de Souza Romero ${ }^{1}$ \\ Márcio Barbosa de Assis 2
}

\section{Apresentação}

Em comemoração aos 10 anos do curso Mestrado Profissional do Programa de Pósgraduação em Educação, da Universidade Federal de Lavras, realizamos uma entrevista com a professora Tania Regina de Souza Romero, professora permanente do Programa de Pósgraduação em Educação e do Programa de Pós-Graduação em Letras da Universidade Federal de Lavras.

A professora Tania Romero marcou presença na implementação do curso de Mestrado Profissional em Educação, em que se firmaram parcerias com os Departamento de Letras, de Educação Física e Ciências Humanas. Atuou como coordenadora adjunta do programa nos anos de 2016-2018, durante a coordenação do professor Vanderlei Barbosa.

Tania Romero é graduada em Letras Tradutores e Intérpretes pelo Centro Universitário Ibero Americano (Português, Inglês e Alemão, 1978). Tem mestrado e doutorado em Linguística Aplicada e Estudos da Linguagem pela Pontifícia Universidade Católica de São Paulo (1989 e 1998) e pós-doutorado em Educação pela Universidade Estadual de Campinas (UNICAMP, 2007). Atualmente é membro do Conselho Editorial de 9

\footnotetext{
1 Pós-doutorado em Educação; Doutora em Linguística Aplicada e Estudos da Linguagem. Universidade Federal de Lavras (UFLA), Lavras, Minas Gerais, Brasil. E-mail: taniaromero@ufla.br.

${ }^{2}$ Mestre em Educação. Universidade Federal de Lavras (UFLA), Lavras, Minas Gerais, Brasil. E-mail: marcio.assis@ufla.br.
} 
Revistas Científicas da área, incluindo Intercâmbio (PUC-SP, 1413-4055), Revista D.E.L.T.A. (PUC-SP, 0102-445) e Revista The ESPecialist (PUC-SP, 0102-7077). É Professora Associada no Departamento de Estudos da Linguagem e professora permanente do Mestrado Profissional em Educação e do Programa de Pós-Graduação em Letras da Universidade Federal de Lavras. Foi vice-coordenadora e coordenadora do Grupo de Trabalho Formação de Educadores na Linguística Aplicada, vinculado à ANPOLL (Associação Nacional de Pós-Graduação e Pesquisa em Letras e Linguística). Pesquisa na área de Linguística Aplicada, com ênfase em Desenvolvimento de Educadores, Educação, EnsinoAprendizagem de Línguas Adicionais, Avaliação de Aprendizagem, Identidade Docente e Linguística Sistêmico-Funcional.

\section{Entrevista $^{3}$}

Márcio: Professora Tania, nesta edição especial, que integra a comemoração de dez anos do Programa de Pós-graduação em Educação, gostaríamos de manifestar nosso reconhecimento pelo trabalho desenvolvido em prol da formação de professores. Relate sobre a sua trajetória profissional e como se deu o direcionamento de seus estudos e de suas pesquisas para o campo da formação de professores.

Tania: Desde pequena eu queria ser professora. Os bons exemplos de professores que tive no primário (era assim chamado na década de sessenta do século passado!) muito colaboraram para isso. Por isso era comum eu brincar de professora em frente a um pequeno quadro que ganhei de presente. Em alguns momentos, pensei também em ser escritora (escrevi alguns contos quando criança) e tradutora. Até fiz faculdade para ser tradutora e intérprete, mas o curso era uma complementação da licenciatura.

Enquanto eu estava no ginásio, dei algumas aulas particulares para colegas e crianças de séries anteriores à minha. Para ter alunos, cobrava só 2 reais! Mais tarde, quando retornei de minha bolsa de estudos nos Estados Unidos, comecei a dar aulas de inglês. Eu gostava

\footnotetext{
${ }^{3}$ Realizada no dia $1^{\circ}$ de junho de 2020, por Márcio Barbosa de Assis (discente egresso do Mestrado Profissional em Educação, da Universidade Federal de Lavras).
} 
disso! Dei aulas tanto particularmente, para alunos individuais, quanto em cursinhos de inglês. Eu achava o máximo dar aulas para médicos, engenheiros, publicitários, empresários e tanta "gente grande" quando eu tinha apenas 18 anos!

Também exerci a função de tradutora, mas, com o tempo, passei a achar muito solitário o trabalho somente com dicionários e o texto. Gostava da interação. Também fui secretária em multinacionais, quando não conseguia ser chamada para nenhuma escola regular para a qual me candidatava em São Paulo.

A vantagem de ser secretária era não levar trabalho para casa, mas havia abuso por parte dos chefes: eu tinha de cuidar de questões pessoais deles também, como ir ao banco no horário de almoço para pagar escola de filhos e prestações, comprar presente para a esposa etc. Quando um deles me pediu para ir comprar cigarro achei demais e decidi que pararia com aquilo assim que pudesse. Mas o salário era bem melhor que o de professora.

Quando, já casada, eu não dependia do meu salário, passei a ser somente professora em cursinhos de inglês, com ocasionais inserções como tradutora freelancer para áreas diferentes (odontologia, psicologia, engenharia, marketing), especialmente para videoclubes (mais tarde chamados vídeo locadoras), quando se iniciava o mercado de videocassetes no Brasil e eram necessários tradutores para preparar as legendas em português. Trabalhei para o primeiro videoclube do Brasil, em São Paulo.

Por um período, enquanto trabalhava durante o dia como correspondente inglêsportuguês em uma multinacional, também dei aulas na faculdade onde me formei. Fiquei muito envaidecida de ter tido a honra de ter sido convidada por meus ex-professores para voltar à minha faculdade. Lá dei aulas de inglês e tradução. Gostei muito, embora tivesse sentido o desafio de lidar com classes grandes, alunos bagunceiros. Na época em que era aluna, o comportamento era mais respeitoso.

Quando eu cursava a faculdade, gostava da disciplina de Linguística, então resolvi fazer mestrado em Linguística Aplicada, na PUC-SP, que ficava perto de onde eu morava. Eu mal sabia à época o que era Linguística Aplicada. Achei o mestrado muito difícil no início, mas gostei porque era um bom passatempo e grande parte dos professores eram estrangeiros, então as aulas eram em inglês. Além disso, isso me tirava da tristeza de ter tido abortos. $\mathrm{Na}$ década de oitenta, quando fiz mestrado, o tempo de conclusão era 5 anos. 
Somente após concluir o mestrado passei a dar aulas no ensino superior. Embora eu tivesse tido aulas de didática na Faculdade, creio que somente após o mestrado passei a entender as bases do processo de ensino-aprendizagem. Tanto que minha dissertação enfocou esse tema. Comecei dando aulas principalmente na Letras, mas também nos cursos de Turismo, Relações Internacionais, Moda, Sistemas de Informação, Biologia, Ciência da Computação. A base que tive no mestrado para ensino instrumental de línguas me foi muito útil ante os desafios para preparar e dar aulas para áreas que não conhecia.

Entre mestrado e doutorado houve um hiato de 5 anos. Naquela época não havia essa febre por formação tão comum atualmente. Nesses 5 anos, meu objetivo era ter filhos. Mas, com sucessivos abortos, lembrei-me que gostava mesmo de estudar e o doutorado me parecia uma vez mais uma saída para me desviar a atenção de dolorosas tentativas. E foi muito importante para me dar um objetivo na vida, um interesse em pesquisar, em me questionar como poderia fazer meu trabalho melhor, mais consciente, como poderia conhecer mais meus alunos, futuros professores, e ajudá-los a se desenvolverem.

Márcio: O trabalho do professor é de grande responsabilidade, deve-se estudar continuamente, atualizar-se com teorias e práticas; é uma atividade que requer muita dedicação, envolvida por pressões de diversas ordens, muitas reuniões, projetos a serem elaborados e, infelizmente, de pouco reconhecimento. Nesse contexto, há vários professores que buscam a qualificação por meio do ingresso em mestrados profissionais. No seu entendimento, quais são as contribuições que um programa de mestrado em educação, na modalidade profissional, pode trazer para a qualificação dos processos educativos e para a formação de professores?

Tania: Não vejo diferença alguma entre mestrado acadêmico e profissional. Comecei a atuar como educadora em programas de pós-graduação acadêmicos e no mestrado profissional desenvolvo e oriento pesquisas exatamente com os mesmos propósitos e do mesmo formato, com os mesmos instrumentos. Meu enfoque é formação de professores, o que entendo como formação continuada. Isso é fundamental para qualquer profissional, especialmente para quem visa ensinar. Costumo dizer que quem quer ser professor precisa ser estudante profissional. 
Márcio: A formação de professores (inicial e continuada) é um campo de estudos relevante nas pesquisas em educação, sobretudo, por passar por muitas ressignificações ao longo do tempo. Em seu campo de pesquisa, você faz reflexões sobre a identidade docente. Que contribuições essas discussões trazem para o processo formativo dos docentes?

Tania: Foi na época do doutorado que aprendi o valor da reflexão, especialmente da reflexão crítica. E um dos instrumentos principais para alavancar reflexões é um exame fundamentado ao percurso de formação, que vai além da instrução formal. É ao longo da vida que vamos tendo experiências marcantes, e o modo como as interpretamos pautam grandemente as escolhas e caminhos que fazemos, além da forma como entendemos o mundo e agimos nele. Essas constatações não foram somente solidificadas com conceitos teóricos (de reflexão crítica, visão vygotskiana e identidade docente), mas com o efeito que tenho observo em meus alunos desde 1997, quando comecei a trabalhar com essa abordagem para a formação continuada de professores. A revisão dos caminhos percorridos tem trazido conscientização e, consequentemente, "preparam" o (futuro) professor para aceitar e percorrer outros caminhos, desta vez mais conscientemente e com o embasamento adequado.

Márcio: Atuando no campo de formação de professores, quais características você considera que são essenciais ao um bom educador?

Tania: (a) ser humilde e flexível para adotar (ou ao menos compreender) outras visões que podem ser diferentes das suas; (b) ser reflexivo; (c) arriscar-se em "mares nunca dantes navegados"; (d) saber ouvir os alunos e entendê-los; (e) ser curioso.

Márcio: Considerando que a formação de professores no Brasil representa um desafio para as instituições formadoras, que sugestões você daria para a qualificação dos processos de desenvolvimento profissional?

Tania: Formação contínua, com discussões que partam da prática. Na Suiça, por exemplo, todo professor precisa fazer curso de formação continuada a cada 2 anos. E fazer curso não significa somente aprender teorias/procedimentos novos. Precisa-se partir da prática que o professor vivencia, considerando os problemas e desafios que enfrenta e como os interpreta. A voz do professor precisa ser ouvida se a meta é transformação. Aprendi com a 


\section{OD DEVIR EDUCAÇÃO \\ ISSN: 2526-849X}

professora Maria Antonieta Alba Celani ${ }^{4}$ que o educador somente ajuda a construir novos enfoques e práticas docentes quando ouve o (futuro)professor e discute com ele a partir dos entendimentos que ele traz. Negociação de significados; construção conjunta, nos dizeres vygotskianos, que também encontram eco na perspectiva freireana.

Márcio: A formação de professores, tanto em sua inflexão inicial quanto à continuada, é um campo de estudos relevante nas pesquisas em educação, sobretudo por passar por muitas ressignificações ao longo do tempo. Em seu campo de pesquisa, há uma relação à autobiografia dos professores. Que contribuições essa experiência pode agregar no processo formativo dos docentes?

Tania: Creio já ter de alguma forma respondido essa pergunta. Repito que acredito fortemente que novos construtos somente são possíveis quando se compreende quais são os construtos atuais que guiam a prática e entendimentos sobre ensino-aprendizagem e formação. Portanto, instrumentos como autobiografia e diários reflexivos são poderosos para se alcançar esse intento e deflagrar reflexões.

\footnotetext{
${ }^{4}$ Educadora e professora emérita da Pontifícia Universidade Católica de São Paulo, fundadora do primeiro Programa de Linguística Aplicada na América Latina.
} 